\title{
Epilepsy and Cortical Malformation Type Schizencephaly: Concerning Two Cases Revealed in Young Adult
}

\section{Eric Gueumekane Bila Lamou ${ }^{1 *}$, Adjaratou Dieynabou Sow ${ }^{1}$, Anna Modji Basse Faye ${ }^{1}$, Yacouba Njankouo Mapoure ${ }^{2}$, Soumaila Boubacar ${ }^{1}$, Ngor Side Diagne ${ }^{1}$, Kamadore Toure ${ }^{1}$, Moustapha Ndiaye ${ }^{1}$, Amadou Gallo Diop $^{1}$ and Mouhamadou Mansour Ndiaye ${ }^{1}$}

${ }^{1}$ Neurological Clinic, Fann Teaching Hospital, Dakar, Fann, Senegal

${ }^{2}$ Douala General Hospital, Cameroon

*Corresponding Author: Eric Gueumekane Bila Lamou, Neurological Clinic, Fann

Teaching Hospital, Dakar, Fann, Senegal.
Received: March 17, 2020

Published: March 30, 2020

(C) All rights are reserved by Eric

Gueumekane Bila Lamou., et al.

\begin{abstract}
Introduction: The Cortical malformations are one of important causes of epilepsy, mental retardation and other neurological disorders. The Schizencephaly is an abnormality of the cortical organization characterized by cracks connecting the pial's surface to the lateral ventricle. Considered as a sporadic anomaly, its genetic origin is likely, involving an EMX2 gene mutation. The clinic depends on the size and location of the slot, and the age of diagnosis.

Patients and Methods: We report clinical observations of a 32-year old woman and a man of 41 years. The Clinical presentation was totally different but they had a single common denominator as seizures with variable onset and type, which were the origin of diagnosis. Their evolution had been variable with drug resistance in one case and a neurosurgical derivation for tetraventricular hydrocephalus.

Discussion and Conclusion: Schizencephaly is a source of earlier onset often focal seizures. Late onset in our case denotes of a certain brain adaptation. Imagery is paramount in the positive diagnosis and the lesional checking.

Keywords: Schizencephaly; Epilepsy; Drug Resistance; Dakar; Senegal
\end{abstract}

\section{Introduction}

Cortical malformations are increasingly recognized as important causes of epilepsy, mental retardation and other neurological disorders [1].

Schizencephaly is a cerebral malformation due to an abnormality of the cortical organization characterized by cracks extending from the pial surface to the lateral ventricle. It is considered as sporadic anomaly, but its genetic origin is probable, implying a mutation of the EMX2 gene [1].

It is a rare disease with an estimated prevalence of 1.54/100000 in India [2]. It represents 3 to $11 \%$ of congenital malformations of the cerebral cortex in Spain [3].

The age of diagnosis is often before the first 15 years [1]. The clinic depends on the size, type and location of the slit. Thus, there are two types. In types I, the cleft is unilateral and the possible manifestations are seizures and hemiparesis. In type II, the cleft is bilateral and there is rather a mental retardation associated with semi-quadricepsis with spasticity and micro- or hydrocephalus [1]

Sectional imaging plays an important role in positive diagnosis, and assessment of prognosis [4].

The treatment of epileptic seizures, often focal, is difficult. Surgery is often impossible because of the central topography of the lesions and the presence of extensive epileptogenic zones [5].

\section{Observation}

Case 1

We report the case of Mrs. K D T, 32 years old, resident in Yembeul, married, mother of 2 children respectively aged 3 years and 8 months.

In his antecedents, we find a notion of head trauma after a cart drop at the age of 6 months. She was hospitalized in the Department of Neurosurgery CHUN Fann for a period of 2 weeks. The na- 
ture of the care was not specified, but the evolution was favorable without sequels at the exit. The psychomotor development was perfectly normal thereafter. There is no notion of familial epilepsy.

The first consultation dates back to the age of 22 for generalized tonic-clonic seizures with post-critical coma with no particular context. The crises had no fixed schedule and occurred at the rate of 3 seizures/day. A consultation in a local hospital leads to the prescription of phenobarbital (Gardenal $100 \mathrm{mg}$ ), 1 tablet/day in the evening. The evolution was marked by a progressive improvement: the daily reduction of the frequency of the crises is $1 \mathrm{crisis} /$ day, then a monthly crisis then the stop of the convulsive crises.

Later, years later, she began to experience breaks in contact with others around her. These caused the frequent fall of her child who was breastfeeding. These crises occurred 2 to 3 times a day. In front of this situation the family decides to consult in our service for better support.

Physical examination, particularly neurological and general condition were normal.

The wakeful EEG revealed the presence of paroxysmal signs of the type of spikes and slow spikes-waves in right parieto-temporal tending to become bilateral and activated by the HPN.

Computed tomography showed a cystic cavity of about $54 \times 57$ $\mathrm{mm}$, cortico-subcortical, right occipital in continuity with the occipital horn of the right lateral ventricle, associated with thinning and partial lysis of the occipital bone opposite. This being in favor of a right Type 1 occipital schizencephaly.

The genetic balance in search of the mutation of the gene EMX2 could not be done, for lack of financial means.

For treatment, sodium valproate (Depakine chrono $500 \mathrm{mg}$ ): 1 tablet morning and 1tablet evening had taken over from phenobarbital.

The evolution was marked after 12 months by the resumption of monthly general convulsive seizures ( 1 to 2 /month) and the disappearance of absence seizures.

\section{Case 2}

This is Mr. SML 41 year's old, resident keur massar, single, and no profession.

In his antecedents we find that from the age of 16 , he had presented recurring paroxysmal episodes of delusional ideas associated with breaks in contact. No consultation had been made. There is no notion of familial epilepsy.

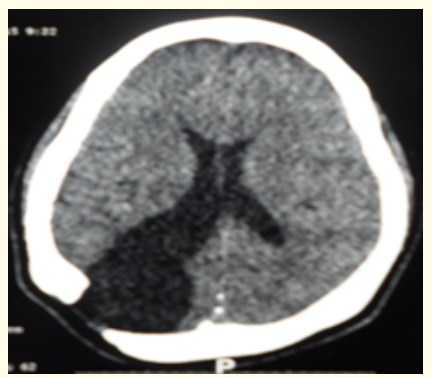

Figure 1: CT scan in axial section without injection of contrast medium showing a right occipital schizencephaly split.

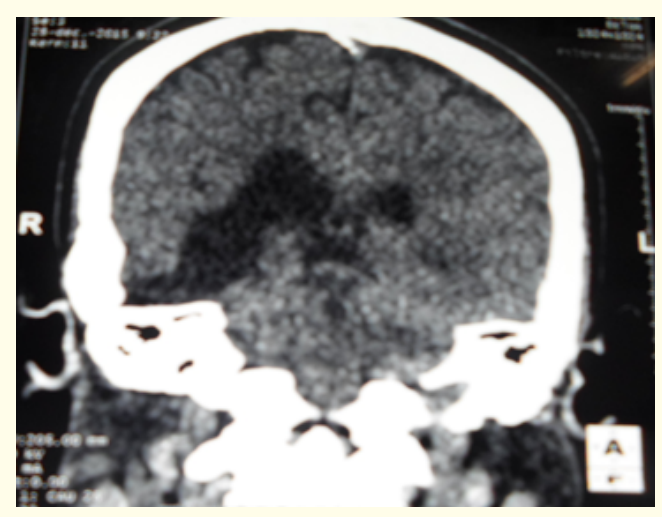

Figure 2: Cerebral CT in coronal section showing right parietal homogeneous hypodensity of liquid allure, starting from the lateral ventricle on the cortical surface.

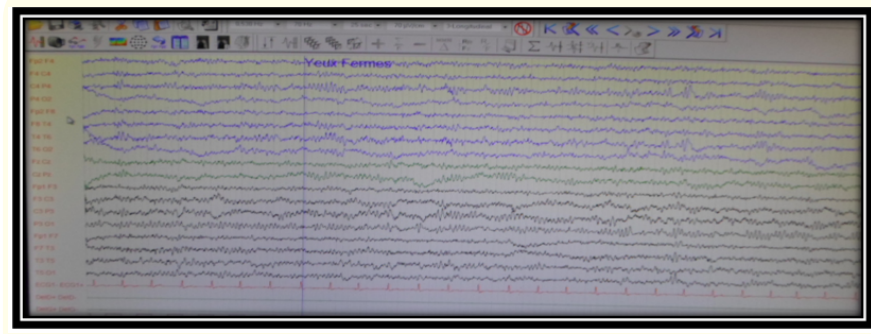

Figure 3: Well-organized EEG wake-up plot for age with paroxysmal focus in right parieto-temporal tending to diffuse.

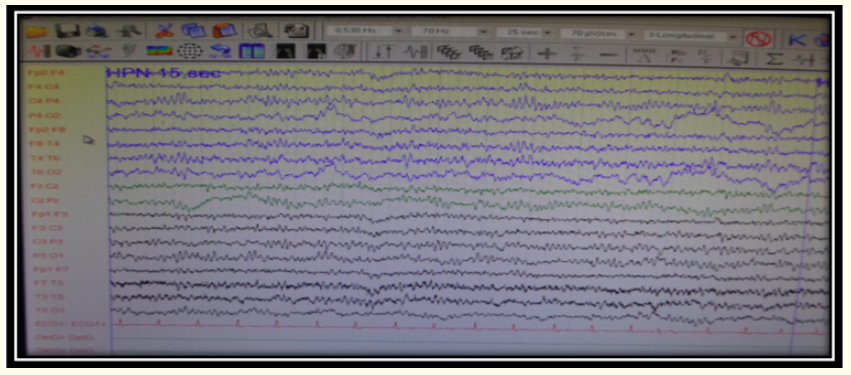

Figure 4: EEG plot of size with HPN a slow down in parieto-occipital right. 
Later, at the age of 31 , the picture was complicated by the appearance of a gait-like walking disorder with no notion of alcohol or drug use; that did not motivate consultation either.

The patient was finally brought into consultation in our department a few months before the onset of generalized tonic-clonic seizures with impaired consciousness.

Indeed the beginning of the symptomatology began by the sudden occurrence of subintrant generalized tonic-clonic convulsive seizures ( 4 crises). This motivated a consultation in a health center where the treatment initiated was undocumented and without crisis remission. Faced with the alteration of his conscience, he is referred to our service for specialized care.

The clinical examination revealed bilateral pyramidal syndrome, Adams and Hakim syndrome, cortical irritation syndrome and macrocranium $(\mathrm{PC}=62 \mathrm{~cm}, \mathrm{VN}=57 \mathrm{~cm})$.

The blood tests were peculiar.

Emergency cerebral CT was consistent with bi-fronto-parietal schizencephaly associated with chronic tri-ventricular hydrocephalus.

MRI confirmed schizencephaly associated with active ventricular tributary hydrocephalus with stenosis of the Sylvius aqueduct.

The EEG standby pattern was quite well organized for age with a pseudo rhythm of the left temporal flap. It should be noted that the activation by the HPN had not been carried out because of the non-cooperation of our patient (fluctuation vigilance, Understanding disorders). Moreover, the EEG sleep pattern, done remotely, was without abnormality.

The treatment consisted of injectable diazepam combined with phenobarbital $100 \mathrm{mg}$ once daily in the evening. In front of hydrocephalus, we added acetazolamide $250 \mathrm{mg}, 1$ tablet $\times 2$ /days; and performed subtractive punctures.

The evolution was favorable intra-hospital clinically with the control of seizures, but we noted the persistence of delusional behavioral disorders; which necessitated the opinion of a psychiatrist.

At the end of his hospitalization in our department we referred him to the neurosurgery department for the management of tri-ventricular hydrocephalus by stenosis of the Sylvius aqueduct.

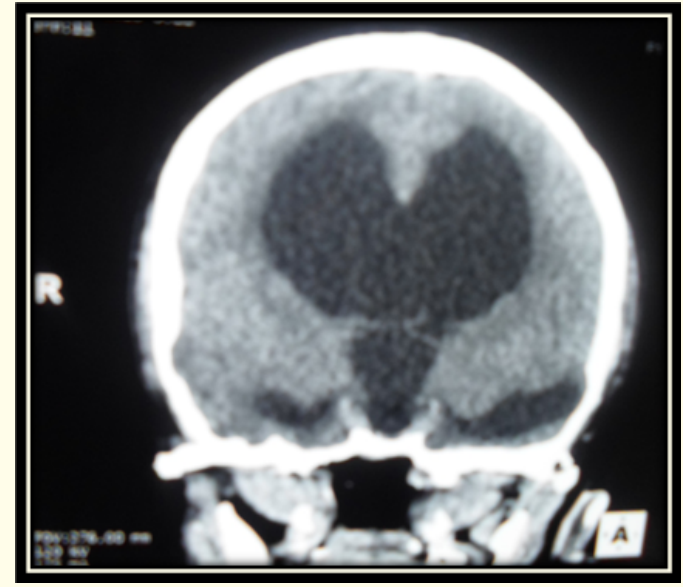

Figure 5: CT scan of brain in coronal section without injection of contrast product show Slit bi-fronto-parietal open on the left and closed on the right associated with a hydrocephalus tri ventricular.

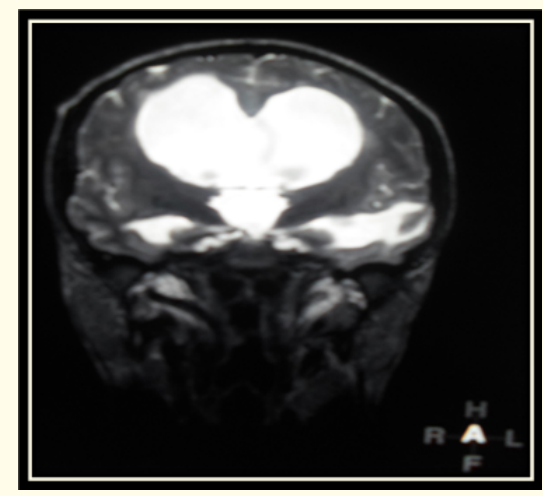

Figure 6: MRI Sequence T2 in coronal section show bilateral cleft associated with a tri ventricular hydrocephalus with stenosis of the aqueduct of Sylvius.

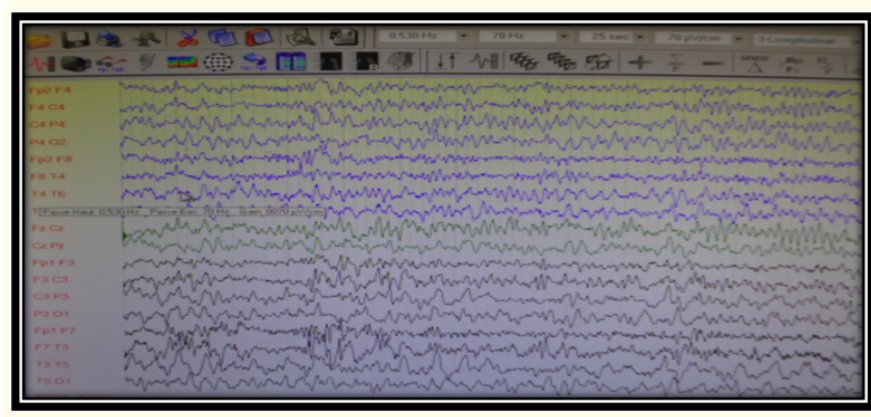

Figure 7: EEG wakefulness rather well organized for the age with irritative signs in front left and a pseudo-rhythm of the shutter in temporal previous left. 


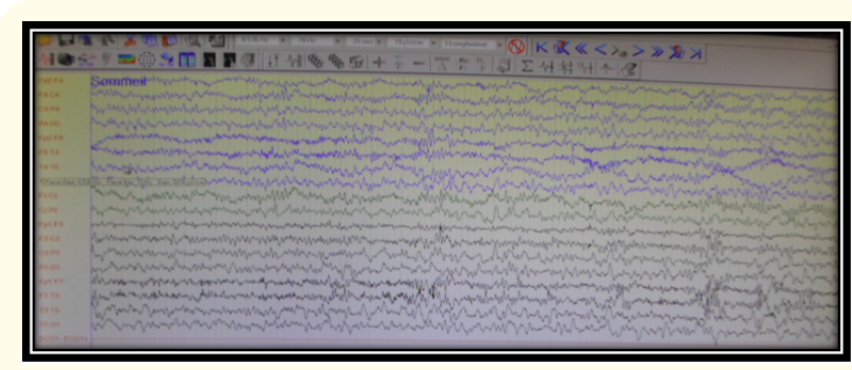

Figure 8: Well-organized sleep pattern without superimposed anomaly with persistence of the rhythm of the left temporal flap.

\section{Discussion}

Schizencephaly corresponds to a unilateral ( $60 \%$ of cases) or bilateral ( $40 \%$ of cases), extension of the lateral ventricle on the surface of the cerebral cortex, with continuity between the pie mater and the ependymal [6-10].

This cleft or "porus" is lined with gray cortical substance often micropolygyric, covered with pie mater. Key element of the diagnosis to differentiate it with a porencephalic cavity [1].

The positive diagnosis of schizencephaly is made by medical imaging MRI or CT [11] and its clinical depends on the size and location of the slit. In post-natal, the most frequently encountered clinical signs are represented by psychomotor retardation and pharmaco-resistant epilepsy, and sectional imaging (CT and MRI) plays a key role in the positive diagnosis and assessment of the lesions [4].

In types I (unilateral cleft), possible manifestations are seizures and hemiparesis. In types II (bilateral cleft), we observe rather a mental retardation associated with a semi-quadricepsis with spasticity and a micro- or hydrocephalus [1].

However, there are open bilateral schizencephaly characterized by atypical clinical presentation and characteristic nuclear magnetic resonance imaging. This is the case of a patient, over 40 , who had never presented a seizure crisis and, although motor disorders are well correlated to brain damage, neurobehavioral disorders were not proportional to MRI images of this cerebral malformation [12-22]. Epilepsy is a chronic pathology that often occurs during childhood and is characterized by the occurrence of recurrent spontaneous epileptic seizures. The onset and presentation of epileptic seizures are largely dependent on neuronal excitability and the balance between excitatory and inhibitory neurotransmission. These factors being determined in particular by the state of cerebral maturation; epileptic seizures are much more common in children than in adults [21].
In the literature epileptic seizures in schizencephaly are often focal [24] and manifest themselves earlier. The cases we have reported show that they can also be found in adulthood, and that we can observe generalized and focal crises. This could be explained by the extent of the malformation with regard to generalized seizures.

Our second observation is consistent with the literature with respect to bilateral schizencephaly in which mental retardation associated with paresis and hydrocephalus was observed. However, he presented generalized tonic-clonic seizures not described in the literature in this form of schizencephaly. The stenosis of the Sylvius aqueduct was demonstrated by MRI explaining its hydrocephalus. However, the relationship between schizencephaly and hydrocephalus needs to be established.

The management of epileptic seizures in schizencephaly remains a great challenge even in developed countries because they are pharmaco-resistant. In our context and specifically in our first case; care is difficult because initially it had generalized seizures and subsequently absences. The socio-economic level is low for the purchase of sodium Valproate, because phenobarbital is contraindicated in case of absence. In the literature, two cases of schizencephaly associated with malformation of the upper limb have been reported. For the first case, it was a 4-year-old boy who had left-sided unilateral cleft schizencephaly associated with longitudinal fore arm ectromelia with a "lobster claw" hand. The Child also had spastic diplegia, intellectual insufficiency and epilepsy. The second case involved a 23-month-old boy with unilateral schizencephaly with a right rolandic cleft, associated with an ectromely of the right hand, a hemiparesis, who presented at 11 years of age a convulsive tonic-clonic seizure. The hypothesis evoked was schizencephaly secondary to localized ischemia of the periventricular germinal matrix occurring around the $7^{\text {th }}$ week of gestation [23]. However, this mechanism cannot be accepted in the second observation with homolateral ectromelia with schizencephaly. The severity of mental disorders and motor deficits are related to the size and location of the cleft; The presence of callous agenesis is a sign of poor prognosis. Surgery is often impossible to perform because of the central topography of the lesions and the presence of extensive epileptogenic zones [24], hence the importance of good monitoring during pregnancy for good management of the most common etiologies. Discussed in our context. This is the case of ischemia in utero, CMV infection or toxoplasma Gondi, and a genetic cause mutation of the EMX2 gene.

\section{Conclusion}

Schizencephaly is a cerebral malformation characterized by cracks extending from the pial surface to the lateral ventricle, its genetic origin is likely implying a mutation of the EMX2 gene. The 
pre- and post-natal diagnostic strategy was revolutionized by sectional imaging, essentially MRI. Her clinic depends on the size and location of the slit. The severity of mental disorders and motor deficits is related to the size and location of the cleft. Epileptic seizures are often focal and difficult to treat. Surgery is often impossible because of the central topography of the lesions and the presence of extensive epileptogenic zones.

We reported 2 rather confusing clinical observations with a clinic partially correlated with the literature but especially with late symptomatic ages.

Our cases call into question the complex genesis of this type of malformation, its aetiopathogenic bases, probably related to intercurrent infections at a given moment of their brain maturation process in our patients. Further etiological research with a more comprehensive perinatal Survey, however, should be more edifying compared to literature data.

\section{Bibliography}

1. Hayashi N., et al. "Morphological features and associated anomalies of schizencephaly in the clinical population: detailed analysis of MR images". Neuroradiology 44.5 (2002): 418-427.

2. Senol U., et al. "Dizygotic Twins with schizencephaly and focal cortical". American Journal of Neuroradiology 21.8 (2000): $1520-1521$

3. Castroviiejo P., et al. "Schizencephaly: A study of 16 patients". Neurologia 27.8 (2012): 491-499.

4. N Cherif Idrissi El Ganouni., et al. "What do you know about schizencephaly? About 11 cases". Radiology Department, Mohamed VI Teaching Hospital, Marrakech, Morocco. JFR (2011): 01292.

5. Granata T., et al. "Schizencephaly: neuroradiologic and epileptogenic findings". Epilepsia 37.12 (1996): 1185-1193.

6. Ozkur A., et al. "Second trimester diagnosis of ostéogénesis imperfecta associated with schizencephaly by sonography". Saudi Medical Journal 28.8 (2007): 1289-1378.

7. The rum M. "Radio-anatomy of the anterior part of the arterial circle of the brain: anatomical variations and aneurysmal pathology". Memory Certificate of Anatomy, Imaging and Morphogenesis, University of Nantes (2011).

8. Muhamed J. "Contribution of MRI in the assessment of malformations of cortical development". Optional specialty memory Radiology Sidi Mohammed Ben Abdellah University (2014).
9. Guerrini R., et al. "Epilepsy and malformations of the cerebral cortex". Neurologia 14.3 (1999): 34-47.

10. Florence G. "The physiology of cerebral circulation". Bulletin de l'Académie Vétérinaire 157.3 (2004).

11. Omezzin Jerbi S., et al. "Schizencephaly of type 1 or closed slit form: appearance in magnetic resonance imaging". Archives de Pédiatrie 17.7 (2012): 762-764.

12. Dies AK., et al. "Schizencephaly: Association with young maternal Age, Alcohol Use, and Lack of Prenatal care". Journal of Child Neurology 28.2 (2013): 198-203.

13. Avcu S., et al. "Bilateral giant open lip schizencephaly with associated cerebral anormalies: a case report". Cases Journal 2 (2009): 7012-7014.

14. Jiddi K., et al. "Imaging Atlas of Brain Malformations in Children: For Dummies". Pediatric radio service CHU Mohamed VI. Mother hospital child Marrakech Morocco (2013).

15. Cottier JP., et al. "Cortical malformations and epilepsy: contribution of MRI". Journal of Radiology 87 (2006): 1621-1654.

16. Coates EE., et al. "A case of schizencephaly associated with obsessive-compulsive disorder". Annals of Clinical Psychiatry 25.2 (2013): 151-152.

17. Christophe C., et al. "Ultrasound and MR imaging in periventricular leukomalacia". Revue Medicale de Bruxelles 3 (2003): 154-161.

18. Hornoy P., et al. "Prenatal detection of brain anomalies with ultrasonography”. Journal of Radiology 92.2 (2011): 111-117.

19. Karen Y., et al. "Fetal schizencephaly: Pré and post natal. Imaging with review of the clinical Manifestations". Radiographics 25.3 (2007): 647-657.

20. Sharma N., et al. "Bilateral schizencephaly Type II". Australasian Medical Journal 7.3 (2014): 157-160.

21. Megiddo L., et al. "Health and economic benefits of public financing of epilepsy treatment in India: An agent-based simulation model". Epilepsia 57.3 (2016): 464-474.

22. M Avellanet., et al. "An unusual clinical presentation of bilateral schizencephaly". Surgical and Radiologic Anatomy 18.4 (1996): 271-273.

23. V Humbertclaude., et al. "Schizencephaly and malformation of the upper limb". Archives of Pediatrics 3.4 (1996): 357-358. 
24. JP Cottier., et al. "Cortical malformation and epilepsy: contribution of MRI". Radiology Journal 87.11 (2006): 1621-1634.

Assets from publication with us

- Prompt Acknowledgement after receiving the article

- Thorough Double blinded peer review

- Rapid Publication

- Issue of Publication Certificate

- High visibility of your Published work

Website: $\underline{w w w}$.actascientific.com/

Submit Article: www.actascientific.com/submission.php

Email us: editor@actascientific.com

Contact us: +919182824667 